\title{
Materials Selection in Gas Turbine Engine Design and the Role of Low Thermal Expansion Materials
}

\author{
BENJAMIN W. LAGOW (id ${ }^{1,2}$ \\ 1.-Rolls-Royce Corporation, Indianapolis, IN, USA. 2.-e-mail: Benjamin.lagow@rolls-royce.com
}

Materials selection criteria in gas turbine engine design are reviewed, and several design challenges are introduced where selection of low coefficient of thermal expansion (CTE) materials can help improve engine performance and operability. This is followed by a review of the types of low CTE materials that are suitable for gas turbine engine applications, and discussion of their advantages and disadvantages. The primary limitation of low CTE materials is their maximum use temperature; if higher temperature materials could be developed, this could result in novel turbine system designs for gas turbine engines.

\section{INTRODUCTION}

A modern gas turbine engine, whether used for aerospace or power generation applications, is made of thousands of components that experience a wide range of stress and temperature conditions. Materials selection requires an understanding of the role that each component plays in the overall operation of the engine. Components may carry high loads, or experience high vibration; some need to be able to resist oil, oxidation, or abrasives entering the engine (e.g., sand). Because the engine uses high-pressure air and burning fuel to generate power, many components experience high temperatures and/or large temperature gradients. The normal operation of a gas turbine engine results in a temperature that varies from ambient at the air inlet to $1000^{\circ} \mathrm{C}$ or more in the turbine (Fig. 1). Depending on the engine architecture, this temperature gradient can happen over a very short distance. These temperature gradients not only introduce high thermal stresses, but actually change the overall engine dimensions: it is not uncommon for an engine to thermally 'grow' several centimeters as it reaches normal operating temperature.

(For more information on the principles and mechanics of gas turbine engines, Ref. 1 is highly recommended.)

Despite the varying environments inside the engine, all of the design decisions for individual components need to result in an engine that meets the customer's requirements. The most important criteria are generally performance (especially as it relates to specific fuel consumption, or SFC), cost, and (mainly for aerospace applications) weight. The relative importance of these will usually be productspecific; for example, a military application may be much more interested in performance over cost. These requirements flow down and become important design criteria for the design of assemblies and of individual parts.

Ultimately, materials selection for an individual component in an engine depends on the relative importance of the various requirements for that component. Most design reviews will concentrate on strength, fatigue capability, weight, and cost; for components in the turbine section, creep resistance and thermal stability also become very important.

For most components, low coefficient of thermal expansion (CTE) is usually not an important requirement. Nevertheless, control of thermal expansion plays an important role in improving the overall performance of the engine. Every decision in the design process is a trade-off between different factors and their effects on the resulting product, and for many components, the positive implications of using a low CTE alloy-and thereby minimizing thermal expansion-are offset by a debit in other properties (for example, corrosion resistance). There are a number of design challenges where the benefits of low CTE alloys can help improve the performance of the engine, but there are also a number of reasons why it is often impractical to use them. 


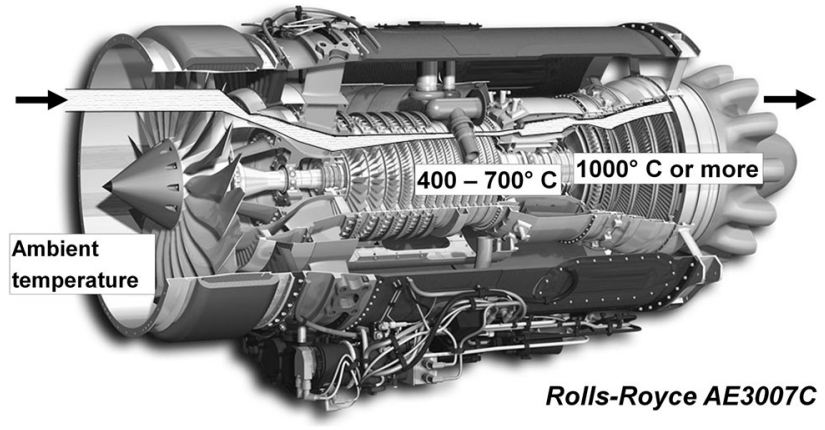

Fig. 1. Cross-sectional view of a Rolls-Royce AE3007C engine. The primary air flow path is highlighted through the engine. The temperature varies from ambient in the front to over $1000^{\circ} \mathrm{C}$ in the combustor and turbine section. (Photo Credit: Rolls-Royce Corporation. All rights reserved).

\section{DESIGN CHALLENGES WHERE LOW CTE ALLOYS ARE USEFUL}

There are two basic reasons why thermal expansion is important in a gas turbine engine: thermal stresses generated in engine components, and control of dimensions in the engine.

\section{Thermal Stress}

Thermal stresses are a consequence of the heat generated during engine operation, which result from both compression of gas and combustion of fuel. When components are attached to each other, or when one component restrains another, any difference in thermal expansion between these components creates stress on one side of the interface, and an opposing stress on the other side.

The thermal stress generated in a component as a function of temperature change, where the component is constrained, is given by the following relationship: ${ }^{2}$

$$
\sigma_{\mathrm{th}}=-\frac{E \alpha}{1-2 v} \Delta T
$$

where $\alpha$ is the coefficient of thermal expansion, $E$ is Young's modulus, and $v$ is Poisson's ratio. The thermal stress is directly proportional to the coefficient of thermal expansion; therefore, low CTE materials will experience less thermal stress for a given temperature change.

In practice, the situation for real engine components is far more complex than this. Most components experience a thermal gradient in the engine; for many components, the temperature difference between the coldest and hottest region can be hundreds of Kelvins. What is more, since the amount of power drawn from the engine varies during service (for example, as an airplane changes from take-off to cruise to landing), these thermal gradients can vary during different stages of engine operation. Some components will cool more quickly than others, as a consequence of material properties
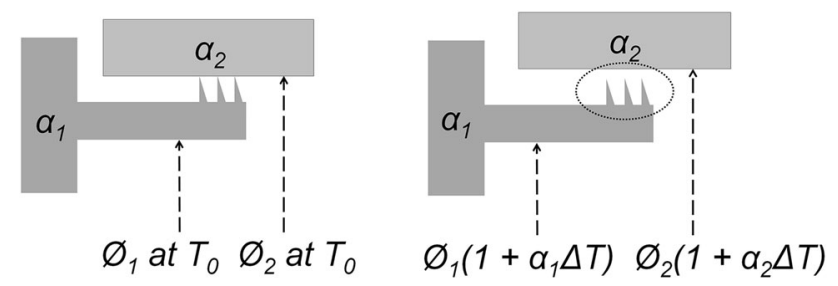

Fig. 2. Differences in thermal expansion lead to gaps (circled) between components as temperatures rise.

(heat capacity and thermal conductivity), geometry, and amount of impinging airflow. Design engineers deal with these complications by using computational modeling methods (computational fluid dynamics and finite element analysis).

\section{Dimensional Control}

A gas turbine engine consists of a collection of rotating assemblies (airfoils, discs, and shafts) inside a static structure. The rotating assemblies drive air through the engine to generate power, and are supported by a system of bearings that requires lubrication. Since there is a temperature gradient in the engine, both front-to-back and radially, the clearances between components will change during operation as a result of thermal expansion and contraction. This leads to two important design considerations: sealing (isolating cavities and preventing air and oil from intermixing) and control of airflow.

Ensuring proper sealing can be a complicated design issue because the temperature profile varies both radially and axially. Figure 2 shows a simplified example of this. The schematic shows the crosssection of two circular components, one seated inside the other, with perfect registry at room temperature. These components are made from materials with different coefficients of thermal expansion. When the system is heated to a uniform temperature, the diameters increase by a different amount, opening a nominal gap of half of the difference. If the outer component were made of a low CTE material, the gap could be minimized or eliminated.

Since oil systems cannot be heated above the temperature at which the oil will begin to coke, the temperature difference cannot exceed a couple of hundred degrees, and this limits the amount of thermal expansion mismatch in air-oil systems. Therefore, the above example is more of an issue for sealing situations where one air cavity must be separated from another, or where gaps between components must be minimized. This is a common situation because airflow into gaps subtracts from the primary air flow of the engine.

The engine generates usable power by compressing air to the correct pressure ratio, mixing that air with an appropriately metered amount of fuel, and drawing power from the expanding gas in the 
turbine. Gaps in the flowpath-whether between or through components-and variations in clearances create losses to secondary flow, with a corresponding loss of efficiency and increase in specific fuel consumption. In an engine, there are many locations where air from the primary flowpath can circulate into secondary flow. This has important ramifications for operating temperature and air pressure around engine components. An example of this is shown in Fig. 3. On the left, the gap between the rotating and static component is tightly controlled. This causes a relatively low pressure inside the cavity, which limits the amount of airflow lost from the primary flow, but at the same time reduces the amount that the airflow can cool the cavity. A wider gap introduces more flow, raising the pressure, and also helps to cool the components. However, the wider gap also subtracts air from the primary flow and reduces the overall performance of the engine.

Since controlling temperature and stress are important design criteria for a component, and strongly affect the selection of material, gap optimization to promote or reduce secondary airflow is an important design activity. Unfortunately, the amount of secondary flow can be difficult to predict due to the complexity of the three-dimensional arrangements of parts. Better control over clearances during the engine cycle can help to reduce the uncertainties, which makes it easier to design for the secondary flow and pressure balance that is needed without sacrificing performance or SFC. Low CTE materials can provide better control of these gaps.

The primary flow of the engine is also directly affected by the clearance between rotating airfoils and static components in compressor and turbine sections (an example is 'tip clearance' in the case between rotating airfoils and the surfaces against which they rotate). A schematic compressor is illustrated in Fig. 4. A typical compressor is a series of rotating disks, with airfoils attached on the outer rim (either as separate components attached in

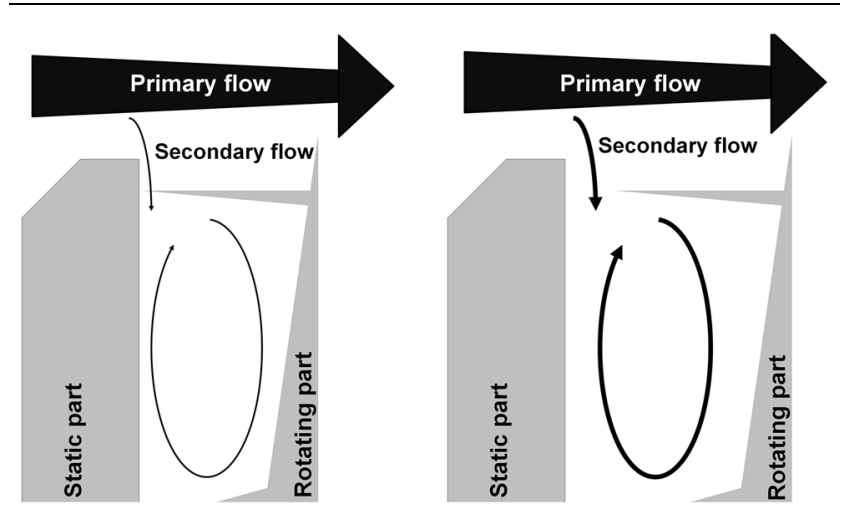

Fig. 3. Air circulation in cavities off of the main flow path is dependent on the size of the gap that allows air to enter from the primary flowpath. The amount of pressure in the cavity, and the subsequent amount of cooling, increases with the size of the gap. slots, or produced by machining or welding to become an integral part of the component). These airfoils rotate through a series of static airfoils, adding work and increasing pressure. As the primary flow travels through the compressor, there are various paths by which compressed air can leak back toward the front of the engine, reducing overall efficiency. The largest path for this leakage is flow between the airfoils and stators. As the clearance around them increases, the efficiency rapidly decreases. $^{3}$ This relationship is shown in Fig. 5 (which is based on data from actual gas turbine engine tests and analysis). Control of this clearance is therefore a critical design concern when trying to maximize performance.

The most straightforward way to prevent leakage flow is to put something in the clearance path; for example, a sealing feature could be machined onto the outer diameter of the discs, which rotates against an abradable material attached to the stators (either directly applied or on a shroud that attaches to the inner diameter). However, since the radial temperature gradient can vary during operation, the amount by which these features interfere with the abradable will change over time. When a sealing feature on the disc grows rapidly, it causes physical damage to the abradable; when the abradable expands, the damage is retained, and the clearance between the seal and the abradable is permanently increased.

One way to minimize this increase is to use materials with low thermal expansion for the static components; the relative increase in separation will be slightly less when the static components are brought to maximum temperature. The low CTE material could be used in the case (which retains the stators), in the stators, or in both components. This is referred to as passive clearance control. Frequently, it is necessary to consider multiple material choices for these types of arrangements, and to perform trade studies based on the results of stress analysis, thermal analysis, and computational fluid dynamics. (Active clearance control systems also

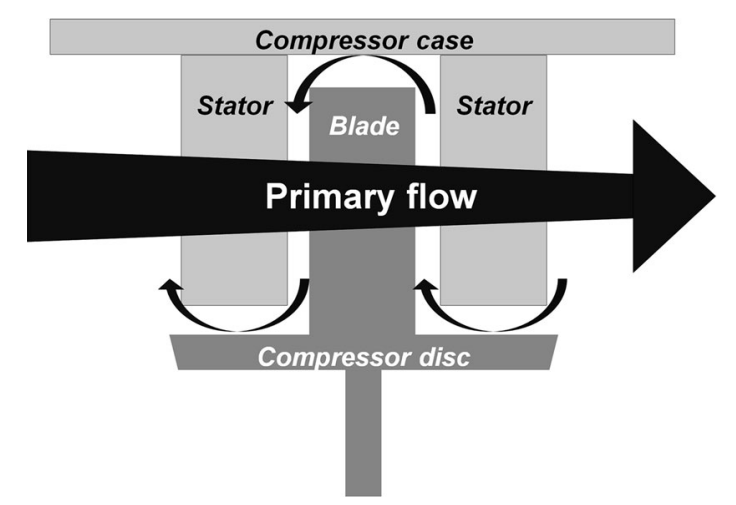

Fig. 4. Schematic of a section of a compressor. The primary air flow is compressed as the rotating disc airfoils force it through the static stator airfoils. Curved arrows indicate leakage flow. 
exist, which use mechanical systems to actively maintain the clearance. These systems are beyond the scope of this article, but it is worth mentioning that since in general they add cost to the engine, where possible, passive control is generally preferred for cost-conscious applications. For a review of this topic, see Ref. 4).

In practice, the situation is more complicated than this. Increasing pressure ratio increases the air temperature toward the back of the compressor, both due to heat generated by compression and heat generated as a result of working against pressure loss due to leakage or windage flow (shear flow against the rotating components that adds work and reduces pressure). Improving the efficiency can help to reduce the temperature by reducing the leakage flow, but that means that cavities that were cooled by the leakage will have higher metal temperatures. Increasing temperatures can drive the need to change the material of components, and since this will change the thermal properties of those components, it will introduce an additional change in the thermal profile. Optimizing a design can therefore be an iterative process, where the benefits of increased efficiency must be weighed against the need to reduce temperature in particular components. (However, there is a practical temperature limit beyond which passive clearance control is not feasible, which will be discussed in the next section.)

Another common compressor geometry is an impeller, commonly used in helicopter engines, for example the Rolls-Royce RR300. In this geometry, the air compression is driven centrifugally through airfoils machined in the forward surface of the impeller (Fig. 6). Similarly to the axial compressor, tight control of the gap between the static shroud and the rotating impeller is necessary for impeller

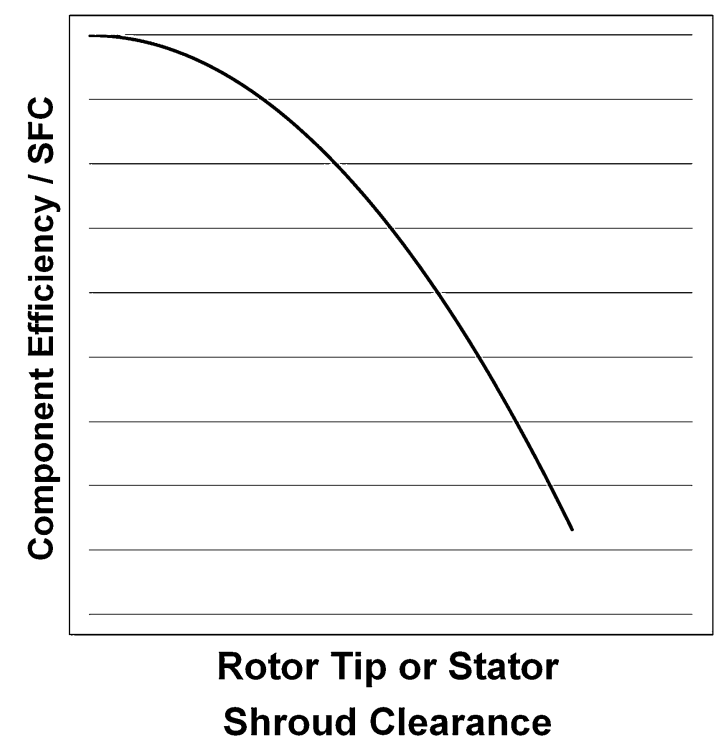

Fig. 5. As the clearance between the static and rotating sections increases, leakage flow also increases, decreasing efficiency. efficiency. However, the geometry adds additional complications to maintaining control. As the impeller spins, compression of air pulls the impeller forward by a reaction force ('air load'). The geometry causes leakage flow in the impeller to be radial. Also, since air temperature rises as it is compressed, there is a large thermal gradient in the impeller, with the highest temperature at the tips (where the pressure ratio is highest). Therefore, the largest thermal expansion is at the tips, which can 'curl' due to temperature asymmetry from the front to the back. It is often necessary to have a larger 'cold clearance' (i.e., clearance before the engine is started) at the tips in order to accommodate the growth.

Controlling the clearance in an impeller is a design challenge. Using low CTE materials for the impeller, for example titanium, helps to reduce the amount of expansion. A low CTE shroud, or a low CTE case holding the shroud in place, can help to control the clearances. This can also be combined with pushing on the tip area with compressed air, or by implementing an active clearance control system.

\section{LIMITATIONS OF LOW CTE ALLOYS}

There are a number of design situations in a gas turbine engine where low CTE materials are useful. Unfortunately, there really are not that many choices for low CTE materials that are viable for engine design, and it is for the same reason that low CTE materials are so desirable: the high temperatures in the engine.

This is illustrated by considering the refractory metals, for example molybdenum and tantalum. They have very low CTE, high melting point, and good mechanical properties; at first glance they might seem an obvious choice for turbine components. Unfortunately, they begin to oxidize at temperatures above $\sim 300^{\circ} \mathrm{C}$, and the rate increases with temperature. ${ }^{5}$ This makes them unsuitable for gas turbine engines; in their useful temperature

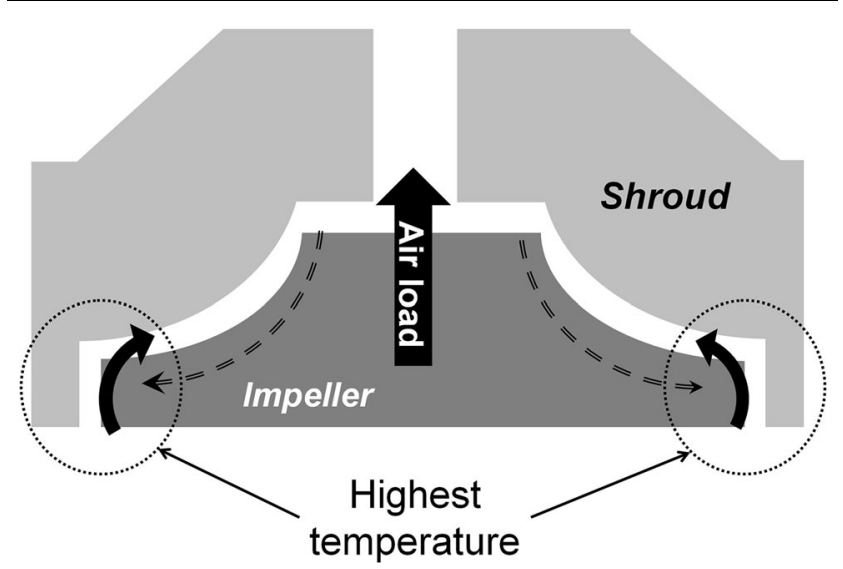

Fig. 6. Schematic of impeller geometry. Dashed lines show direction of airflow through the airfoils. The highest pressure ratio, and highest temperatures, occur at the tip at the exit side of the impeller. Curved arrows indicate tip curling due to thermal gradients. 
range, a titanium alloy (significantly lower weight) or a low- to medium-chrome steel (lower weight and significantly lower cost) would be a much better choice. Coating technologies could be employed to make use of refractory metals possible, but the coatings would need to be highly damage-resistant; any break in the coating would be susceptible to oxidation. CTE mismatch between the coating and substrate would also be an issue.

Table I lists several types of low CTE alloys that are suitable for use in gas turbine applications. There are a limited number of commercially-available alloys with use temperatures above $\sim 550^{\circ} \mathrm{C}$. (Individually named alloys are listed for comparison purposes; their inclusion here is not meant to be an endorsement over other, unmentioned alloys.) In general, this is due to issues with thermal stability of strengthening phases as the application approaches or exceeds the precipitation heat treatment temperature. ${ }^{6,7}$ The maximum use temperature listed is usually application-specific; for example, at very high stress, the maximum temperature allowable may be lower as a result of the potential for creep. Note that the properties of ceramics and ceramic matrix composites (CMCs) are highly variable depending on composition and, in the case of CMCs, design.

The limitations of low CTE materials have important ramifications for the design of the hottest parts of the engine, especially the turbine section.

\section{DISCUSSION}

Current alloys have issues with oxidation and/or creep in the $600-800^{\circ} \mathrm{C}$ range. This temperature range is common in the next generation of compressors, which tend to have higher pressure ratios than the previous generation. The higher pressure also increases the hoop stress of components such as cases, so creep resistance is an important factor. Improvements in alloys in this temperature range would enable better optimization for these applications; whether this optimization would be commercially viable would depend on whether significant cost is added to the alloy raw materials or to subsequent processing (e.g., heat treatment).

Table I. Categories of low CTE materials suitable for use in gas turbine engine applications

\begin{tabular}{|c|c|c|c|c|}
\hline Material & $\begin{array}{l}\text { Maximum use } \\
\text { temperature }\end{array}$ & CTE, $20^{\circ} \mathrm{C}(1 / \mathrm{K})$ & Advantages & Limitations \\
\hline $64 \mathrm{FeNi}\left(\operatorname{Invar}^{\circledR}\right)^{8}$ & $\sim 350^{\circ} \mathrm{C}$ & $\sim 1.3$ & Very low CTE & $\begin{array}{l}\text { Limited corrosion resistance } \\
\text { Limited temperature capability }\end{array}$ \\
\hline $\begin{array}{l}\text { Ferritic or martensitic } \\
\text { stainless steels }\end{array}$ & $\sim 500^{\circ} \mathrm{C}$ & $\sim 10$ & $\begin{array}{l}\text { Low cost } \\
\text { High strength }\end{array}$ & Limited corrosion resistance \\
\hline Titanium alloys ${ }^{10}$ & $\sim 500^{\circ} \mathrm{C}$ & $\sim 8$ to 9 & $\begin{array}{l}\text { High strength } \\
\text { Low density }\end{array}$ & High cost \\
\hline $\begin{array}{l}\text { Iron-nickel superalloys } \\
\text { (e.g., Incoloy }{ }^{\circledR} 909 \\
\left.\text { Thermo-Span }{ }^{\circledR}\right)^{6,11}\end{array}$ & $550-650^{\circ} \mathrm{C}$ & $\sim 8$ & High strength & $\begin{array}{l}\text { Limited oxidation } \\
\text { resistance (can be improved } \\
\text { with } \mathrm{Cr} \text { addition })^{11}\end{array}$ \\
\hline $\begin{array}{l}\text { Advanced low CTE } \\
\text { nickel superalloys } \\
\text { (e.g., Incoloy }{ }^{\circledR} 783, \\
\left.\text { Haynes }^{\circledR} 242^{\circledR}\right)^{7,12,13}\end{array}$ & $\sim 750^{\circ} \mathrm{C}$ & $\sim 10$ & High strength & $\begin{array}{c}\text { High cost } \\
\text { Creep at high temperatures } \\
\text { Dimensional stability } \\
\text { (for some alloys) }\end{array}$ \\
\hline Titanium aluminides ${ }^{10,14}$ & $600-760^{\circ} \mathrm{C}$ & $\sim 12$ & $\begin{array}{l}\text { Low density } \\
\text { High strength } \\
\text { High stiffness } \\
\text { Excellent } \\
\text { oxidation resistance }\end{array}$ & $\begin{array}{l}\text { High cost } \\
\text { Poor ductility }\end{array}$ \\
\hline Ceramics $^{15}$ & Greater than $1000^{\circ} \mathrm{C}$ & $2-10$ & $\begin{array}{l}\text { High specific strength } \\
\text { Low density }\end{array}$ & $\begin{array}{l}\text { Poor fracture toughness } \\
\text { Poor ductility }\end{array}$ \\
\hline $\mathrm{CMCs}^{16}$ & Greater than $1000^{\circ} \mathrm{C}$ & $2-10$ & $\begin{array}{l}\text { High specific strength } \\
\text { Low density }\end{array}$ & High cost \\
\hline
\end{tabular}

For comparison, the CTE of Inconel 718 at room temperature is $\sim 131 / \mathrm{K}$; for A286 and austenitic stainless steels it is $\sim 171 / \mathrm{K}$. (Invar ${ }^{\circledR}$ is a registered trademark of Aperam Alloys Imphy Joint Stock Company. INCONEL ${ }^{\circledR}$ and INCOLOY ${ }^{\circledR}$ are registered trademarks of the Special Metals Corporation. Thermo-Span ${ }^{\circledR}$ is a registered trademark of CRS Holdings Inc., a subsidiary of Carpenter Technology Corporation. Haynes ${ }^{\circledR} 242^{\circledR}$ is a registered trademark of Haynes International, Inc.). 
In general, the hottest temperatures outside of the combustion liner are experienced by the components of the high pressure turbine, which converts the thermal energy from the expanding hot air into rotational energy. It is this rotational energy that drives the high pressure compressor, so turbine efficiency directly affects the overall efficiency of the engine. It is in this region where the benefits of passive clearance control by low CTE materials would be the most useful. Unfortunately, as is evident from Table I, there are currently no available metallic alloys with low CTE that are usable at common turbine temperatures, which can easily exceed $760^{\circ} \mathrm{C}$. Ceramic matrix composites can help to bridge that gap, and are currently being used or considered for a wide variety of applications in the gas turbine industry. ${ }^{16}$ However, their cost and development time remain high, and this leads to a trade-off in cost and development time.

Development of metallic materials with low CTE that are usable at temperatures exceeding $800^{\circ} \mathrm{C}$ would allow major performance optimizations for turbine sections. Since this could potentially avoid the long development time required for CMCs, cost would be less of an issue. Pushing the temperature even higher could revolutionize turbine design, enabling novel designs for future high efficiency turbine sections.

\section{CONCLUSION}

Low coefficients of thermal expansion materials are useful in solving a number of design issues that arise in gas turbine engines. However, most common alloys are limited to use at temperatures below $750^{\circ} \mathrm{C}$, which prevents them from being used in the hottest parts of the engine. Research into alloys that could be used at higher temperatures could permit better optimization and possibly even novel designs for gas turbine engine hot sections.

\section{ACKNOWLEDGEMENTS}

The author would like to thank Dr. Jason Jacobs for helpful discussions and advice on fluid dynamics and engine performance.

\section{REFERENCES}

1. R. Dennis, The Gas Turbine Handbook (US Department of Energy, 2006), http://www.netl.doe.gov/research/coal/en ergy-systems/turbines/publications/handbook. Accessed 11 May 2016.

2. R.B. Hetnarski and M. Reza Eslami, Thermal StressesAdvanced Theory and Applications (New York, NY: Springer, 2009), pp. 110-113.

3. I.N. Moyle, Report No. AA-92-001CR, Naval Postgraduate School, Monterey, CA, 1991.

4. S.B. Lattime and B.M. Steinetz, Report No. NASA/ TM-2002-211794, NASA Center for Aerospace Information, Hanover, MD, 2002.

5. J.R. DiStefano, B.A. Pint, and J.H. DeVan, Int. J. Refract. Met. Hard Mater. 18, 237 (2000).

6. S. Mannan, S. Patel, and J. Barbadillo, Superalloys 2000, ed. T.M. Pollock, R.D. Kissinger, R.R. Bowman, K.A. Green, M. McLean, S. Olson, and J.J. Schirm (Warrendale, PA: TMS, 2000), p. 449.

7. S.K. Mannan, G.D. Smith, and S.J. Patel, Superalloys 2004, ed. K.A. Green, T.M. Pollock, and H. Harada (Warrendale, PA: The Minerals, Metals \& Materials Society, 2004), p. 627.

8. E.L. Frantz, ASM Handbook Volume 2, Properties and Selection: Nonferrous Alloys and Special-Purpose Materials (Materials Park, OH: ASM International, 1990), p. 889 .

9. S.D. Washko and G. Aggen, ASM Handbook Volume 1, Properties and Selection: Irons, Steels, and High-Performance Alloys (Materials Park, OH: ASM International, 1990), pp. 841-907.

10. M.J. Donachie, Titanium: A Technical Guide, 2nd ed. (Materials Park, OH: ASM International, 2000).

11. E.A. Wanner and D.A. DeAntonio, Superalloys 1992, ed. S.D. Antolovich, R.W. Stusrud, R.A. MacKay, D.L. Anton, T. Khan, R.D. Kissinger, and D.L. Klarstrom (Warrendale, PA: TMS, 1992), p. 237.

12. S.K. Srivastava, Superalloys 1992, ed. S.D. Antolovich, R.W. Stusrud, R.A. MacKay, D.L. Anton, T. Khan, R.D. Kissinger, and D.L. Klarstrom (Warrendale, PA: TMS, 1992), p. 227.

13. M. Fahrmann, S.K. Srivastava, and L.M. Pike, Superalloys 2012, ed. E.S. Huron, R.C. Reed, M.C. Hardy, M.J. Mills, R.E. Montero, P.D. Portella, and J. Telesman (Warrendale, PA: TMS, 2002), doi:10.1002/97811185164 $30 . \operatorname{ch} 85$.

14. Y.-W. Kim, JOM 47, 39 (1995).

15. M.M. Gauthier, eds., Engineered Materials Handbook Desk Edition (Materials Park, OH: ASM International, 1995), pp. 979-990.

16. T.E. Steyer, Int. J. Appl. Ceram. Technol. 10, 389 (2013). 